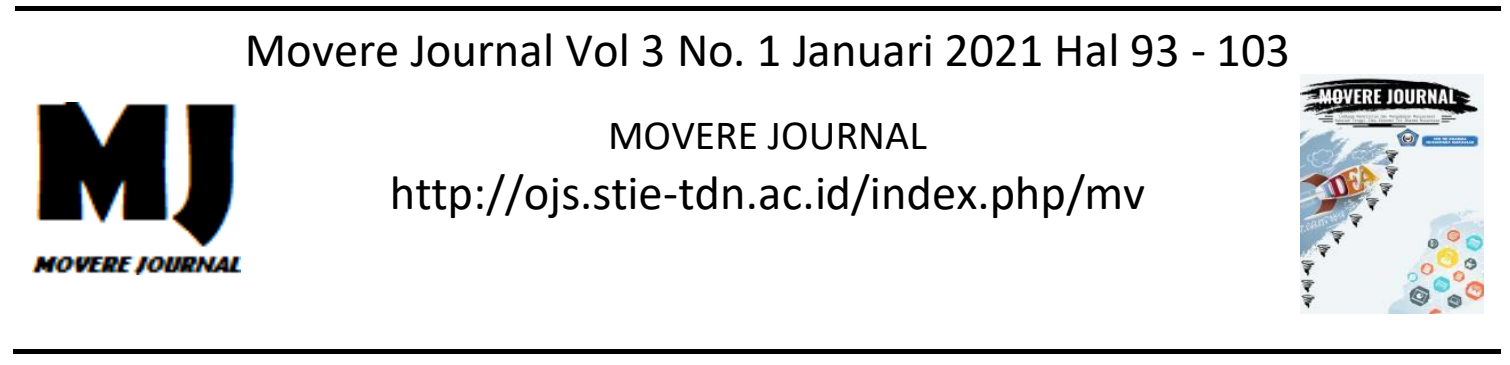

\title{
Analisis Persepsi Mahasiswa Akuntansi Terhadap Sistem Elektronik Nomor Faktur (E-NoFa) (Studi Kasus pada Mahasiswa STIE AMKOP Makassar)
}

\author{
Muhammad Dedy Miswar ${ }^{1}$, Anni Suryani² \\ Sekolah Tinggi Ilmu Ekonomi Amkop Makassar ${ }^{1,2}$
}

\begin{abstract}
Abstrak : Penelitian ini bertujuan untuk mengetahui pengaruh manfaat penerapan sistem elektronik nomor faktur $(E-N o F a)$, kemudahan penggunaan sistem elektronik nomor faktur $(E-N o F a)$ dan kepuasan pengguna sistem elektronik nomor faktur terhadap presepsi mahasiswa. Populasi dalam penelitian ini adalah mahasiswa akutansi STIE AMKOP Makassar. Sampel yang diambil sebayak 75 mahasaiswa Akuntansi. Metode analisis yang digunakan adalah regresi sederhana. Hasil dari penelitian ini menemukan bahwa manfaat penerapan sistem elektronik nomor faktur $(E-N o F a)$, kemudahan penggunaan sistem elektronik nomor faktur $(E-N o F a)$ dan kepuasan pengguna sistem elektronik nomor faktur terhadap presepsi mahasiswa.
\end{abstract}

Kata Kunci : Manfaat, Kemudahan, Kepuasan, Persepsi.

\begin{abstract}
Abstrack : This study aims to determine the effect of the benefits of implementing an electronic invoice number system (E-NoFa), the ease of using the electronic invoice number system $(E-N o F a)$ and the satisfaction of the user electronic system invoice number on the students' perceptions. The population in this study are the students of Accounting at STIE AMKOP Makassar. The sample taken is 75 students of Accounting. The analysis method used is simple regression. The results of this study found that the benefits of implementing an electronic invoice number system (E-NoFa), the ease of using the electronic invoice number system (E-NoFa) and the satisfaction of the user electronic system invoice number toward the students' perceptions.
\end{abstract}

Keywords: Benefits, Ease, Satisfaction, Perception.

\section{PENDAHULUAN}

Modernisasi administrasi perpajakan dilakukan sebagai bentuk peningkatan pelayanan terhadap wajib pajak. Ketentuan, prosedur dan aktivitas perpajakan diarahkan untuk mengubah paradigma perpajakan yang 
semula dianggap sebagai beban kuantitatif menjadi kewajiban partisipatif (Noviani, 2016). Manfaat yang dapat diperoleh da ri penerapan sistem modernisasi administrasi perpajakan bagi Wajib Pajak adalah simplicity, dimana alur pekerjaan lebih sederhana dengan bantuan Account Representative; certainity yaitu terdapat kepastian dalam melaksanakan peraturan perpajakan didukung bidang pelayanan dan penyuluhan di Kanwil serta seksi pelayanan di KPP (Aprilina, 2012).

Modernisasi administrasi perpajakan dilakukan oleh Direktorat Jendral Perpajakan sebagai bentuk peningkatan pelayanan pajak terhadap wajib pajak. Penomoran faktur secara manual dinilai masih memiliki kelemahan khususnya bagi pengusaha kena pajak yang menentukan sendiri nomor faktur pajaknya, sementara terdapat oknum tertentu yang melakukan tindakan kecurangan dengan membuat faktur pajak fiktif, faktur pajak yang tidak dilaporkan dan ada beberapa nomor faktur pajak yang ganda atau sama dengan wajib pajak yang lain. Agar dapat meminimalisir beredarnya faktur pajak fiktif, faktur pajak yang tidak dilaporkan oleh wajib pajak dan ada beberapa nomor faktur pajak yang ganda atau sama dengan wajib pajak yang lain, maka Direktorat Jendral pajak menerapkan sistem penomoran faktur elektronik ( $e-N o f a$ ).

Berdasarkan data dari DJP, selama tahun 2013 s/d 2018 tercatat ada 100 kasus faktur pajak yang menyebabkan kerugian mencapai Rp. 1.461 Milyar (Direktorat Jenderal Pajak, 2018). Penyalahgunaan faktur pajak tersebut disebabkan karena lemahnya pengawasan yang dilakukan oleh DJP, khususnya dalam hal penomoran faktur pajak. PKP sejauh ini diberikan wewenang untuk menuiskan sendiri nomor seri faktur pajaknya dalam transaksi yang dilakukan, sehingga kebijakan tersebut disalahgunakanHasil penelitian yang dilakukan oleh Gisbu, dkk. (2015) menunjukkan bahwa modernisasi $E$ NoFa PPN berpengaruh positif dan signifikan terhadap kepatuhan Pengusaha Kena Pajak.

Hasil penelitian yang dilakukan oleh Salim (2009) menunjukkan bahwa penerapan sistem online dan modernisasi dalam sistem perpajakan terbukti berpengaruh dalam meningkatkan kepatuhan dan kepercayaan masyarakat dalam melakukan pelaporan dan pembayaran pajak. Hasil penelitian yang dilakukan oleh Noviani (2016) juga menunjukkan bahwa implementasi E-NoFa berpengaruh positif dan signifikan terhadap penerimaan PPN barang dan jasa. Hal tersebut dapat mencerminkan bahwa implementasi E-Nofa dapat mempengaruhi kepatuhan Pengusaha Kena Pajak dalam melaksanakan kewajibannya di bidang perpajakan, khususnya yang berkaitan dengan PPN barang dan jasa. tinggi tingkat kepatuhan wajib pajak.

Persepsi timbul karena adanya dua faktor baik internal maupun eksternal. 
faktor internal tergantung pada proses pemahaman sesuatu termasuk di dalamnya sistem nilai, tujuan, kepercayaan dan tanggapannya terhadap hasil yang dicapai. faktor eksternal berupa lingkungan. kedua faktor ini menimbulkan persepsi karena didahului oleh suatu proses yang dikenal dengan komunikasi.

Seperti dikatakan krech (dalam thoha, 2000:124) persepsi adalah suatu proses kognitif yang kompleks dan mengahasilkan suatu gambar unik tentang kenyataan yang barangkali berbeda dari kenyataannya. Persepsi menurut Suharnan (2005:23) merupakan suatu proses menginterpretasi atau menafsirkan informasi yang diperoleh melalui sistem alat indera manusia. Persepsi adalah suatu proses penggunaan pengetahuan yang telah dimiliki (yang disimpan di dalam ingatan) untuk mendeteksi atau memperoleh dan menginterpretasi stimulus (rangsangan) yang diterima oleh alat indera seperti mata, telinga, dan hidung menurut Matlin (1989) dan Solso (1988) dalam Suharnan.

Menurut Undang-Undang No. 28 Tahun 2007 tentang perubahan ketiga atas Undang-Undang No. 6 Tahun 1983 tentang Ketentuan Umum dan Tata Cara Perpajakan (KUP), pajak adalah kontribusi wajib pajak kepada negara yang terutang oleh orang pribadi atau badan yang bersifat memaksa berdasarkan Undang-Undang dengan tidak mendapatkan imbalan secara langsung dan digunakan untuk keperluan negara bagi sebesarbesarnya kemakmuran rakyat.

Menurut Tjahyono dan Fakhri (2005) dalam Imelda (2014:2), pajak adalah suatu kewajiban menyerahkan sebagian daripada kekayaan ke kas negara disebabkan suatu keadaan, kejadian dan perbuatan yang memberikan kedudukan tertentu, tetapi bukan sebagai hukuman, menurut peraturan yang ditetapkan pemerintah serta dapat dipaksakan tetapi tidak ada jasa timbal balik dari negara secara langsung, untuk memelihara kesejahteraan umum.

Dari definisi tersebut, Mardiasmo (2011:1) menyimpulkan bahwa pajak memiliki unsur - unsur pokok yaitu : 1 . Iuran atau pungutan dari rakyat kepada negara. 2. Pajak yang dipungut berdasarkan atau dengan kekuatan undang - undang serta standar aturan pelaksanaannya. 3. Pajak dapat dipaksakan. 4. Tidak menerima atau memperoleh jasa timbal atau kontraprestasi secara langsung. 5. Digunakan untuk membiayai pengeluaran umum pemerintah yang bermanfaat bagi masyarakat luas.

Fungsi pajak merupakan kegunaan pokok dan manfaat pokok dari pajak itu sendiri. Mardiasmo (2011:1) dalam Putri berpendapat pajak mempunyai dua fungsi, yaitu : 1. Fungsi budgetair (Sumber Keuangan Negara) 2. Fungsi regulerend (Pengaturan). Wajib pajak menurut Mardiasmo (2011:23) adalah orang pribadi atau badan, meliputi pembayaran pajak, pemotong pajak, dan pemungut pajak, yang mempunyai 
hak dan kewajiban perpajakan sesuai dengan ketentuan peraturan perundang - undangan perpajakan.

Subjek pajak adalah istilah dalam peraturan perundang-undangan perpajakan untuk perorangan (pribadi) atau organisasi (kelompok) berdasarkan peraturan perundangundangan perpajakan yang berlaku. Seseorang atau suatu badan merupakan subjek pajak, tapi bukan berarti orang atau badan itu punya kewajiban pajak. Kalau dalam peraturan perundangundangan perpajakan tertentu seseorang atau suatu badan dianggap subjek pajak dan mempunyai atau memperoleh objek pajak, maka orang atau badan itu jadi punya kewajiban pajak dan disebut wajib pajak. Subjek Pajak menurut Waluyo (2007:57) ialah sebagai berikut: 1. Orang pribadi 2 . Warisan yang belum terbagi sebagai satu kesatuan 3) Bentuk Usaha Tetap.

Dalam perpajakan, yang dimaksud dengan objek pajak yaitu apa-apa yang dikenakan pajak. Mengingat penting dan strategisnya objek pajak dalam perpajakan, baik hukum maupun akuntansi, sehingga dalam UU perpajakan Indonesia dengan tegas. Dalam website pemerintah pengurus dan pengelola pajak negara dinyatakan bahwa Objek Pajak adalah penghasilan yaitu setiap tambahan kemampuan ekonomis yang diterima atau diperoleh Wajib Pajak, baik yang berasal dari Indonesia maupun dari luar Indonesia, yang dapat dipakai untuk konsumsi atau untuk menambah kekayaan Wajib Pajak yang bersangkutan, dengan nama dan dalam bentuk apapun. Menurut Waluyo (2008: 65) mengartikan objek pajak sebagai berikut. 1. Penghasilan, 2. Laba usaha 3. Hadiah dari Undian atau pekerjaan, 4) Keuntungan karena penjualan atau karena pengalihan harta dan 5) Deviden.

Definisi Nomor Faktur adalah Nomor seri faktur pajak adalah nomor seri yang diberikan Direktorat Jenderal Pajak (DJP) kepada Pengusaha Kena Pajak dengan mekanisme tertentu. Bentuk nomor seri faktur pajak berupa kumpulan angka, huruf, atau kombinasi angka dan huruf yang ditentukan oleh DJP.

Definisi Elektronik Nomor Faktur, Penomoran seri faktur pajak bertujuan untuk mempermudah pengadministrasian setiap transaksi yang dilakukan oleh PKP. Pada awalnya penomoran seri faktur pajak dilakukan sendiri oleh wajib pajak. Wajib pajak memiliki wewenang untuk memberi nomor seri faktur pajak dan melaporkannya, namun, beberapa tahun terakhir terjadi penyelewengan pajak yang disebabkan oleh faktur pajak fiktif. Direktorat Jenderal Pajak terus melakukan upaya untuk mencegah penyelewengan tersebut. Salah satu upaya yang dilakukan adalah dengan menerbitkan e-NoFa. Perbedaan $e-N o F a$ dengan penomoran seri faktur pajak sebelumnya yaitu terletak pada proses penomorannya. Penerbitan e-NoFa dilakukan secara terpusat oleh Direktorat Jenderal Pajak melalui KPP tempat wajib pajak 
terdaftar. Proses permintaannya harus sesuai dengan peraturan. Elektronik Nomor Faktur $(e-N o F a)$ adalah sistem atau aplikasi baru penomoran faktur pajak yang disediakan Direktorat Jenderal Pajak (DJP) bagi wajib pajak untuk melakukan permintaan nomor seri faktur pajak secara elektronik atau online (Puspa, 2017).

Tujuan Utama di berlakukannya $e$ NoFa Pemberlakuan e-Faktur dimaksudkan untuk memberikan kemudahan, kenyamanan, dan keamanan bagi Pengusaha Kena Pajak (PKP) dalam melaksanakan kewajiban perpajakan khususnya pembuatan Faktur Pajak. Pengusaha Kena Pajak (PKP) yang diwajibkan membuat Faktur Pajak berbentuk elektronik ditetapkan dengan Keputusan Direktur Jenderal Pajak. Manfaat E-NoFa. Widodo dan Putu (2015) manfaat $e$ NoFa bagi Pengusaha Kena Pajak, dalam PER 16/PJ2014

\section{METODE PENELITIAN}

\section{A. Waktu}

Penelitian ini akan dilaksanakan selama 1 tahun dari bulan Januari Desember 2020 di STIE Amkop Makassar.

\section{B. Jenis dan sumber data}

Jenis dan sumber data yang digunakan dalam penelitian ini adalah data kuantitatif dengan jenis penelitian explanatory research. Teknik pengumpulan data yaitu observasi dan wawancara.

\section{Populasi dan Sampel}

Populasi penelitian ini pada beberapa mahasiswa akuntansi STIE AMKOP Makassar dan sekaligus sebagai pelaku usaha Dalam penelitian ini, peneliti mengambil 75 sampel mahasiswa Program Studi Akuntansi STIE AMKOP Makassar dan mereka sekaligus sebagai pelaku usaha.

\section{Pengolahan dan Analisis Data}

Pengolahan data dilakukan dengan menggunakan tabulasi dan persentase. Analisis yang digunakan adalah analisis data kuantitatif dengan pendekatan skala Likert yang diperoleh dari daftar pertanyaan yang digolongkan ke dalam lima tingkatan sebagai berikut.

a. Jawaban sangat tidak setuju $=1$

b. Jawaban tidak setuju $=2$

c. Jawaban netral $=3$

d. Jawaban setuju $=4$

e. Jawaban sangat setuju $=5$

Model analisis regresi tunggal yang digunakan untuk menganalisis pengaruh manfaat penerapan sistem elektronik nomor faktur $(E-N o F a)$, kemudahan penggunaan sistem elektronik nomor faktur (E-NoFa), kepuasan pengguna sistem elektronik nomor faktur terhadap Persepsi mahasiswa adalah:

$\mathrm{Y}=\mathrm{a}+\mathrm{bX}$

Keterangan :

$\mathrm{Y}=$ Persepsi mahasiswa

$\mathrm{X}=$ Manfaat penerapan sistem elektronik nomor faktur (E$\mathrm{NoFa}$ ), Kemudahan 
penggunaan sistem elektronik nomor faktur (E-NoFa) dan Kepuasan pengguna sistem elektronik nomor faktur

$\mathrm{a}=$ Konstanta

$\mathrm{b}=$ Koefisien regresi

\section{HASIL ANALISIS DAN PEMBAHASAN}

\section{Analisis Persepsi mahasiswa akuntansi terhadap manfaat penerapan sistem elektronik nomor faktur $(\mathrm{E}-\mathrm{NoFa})$}

Dari analisis yang dilakukan, dapat diketahui bahwa responden menyatakan setuju penerapan sistem elektronik nomor faktur (E-NoFa) merupakan system yang bermanfaat. Hal ini dilihat dari hasil rata-rata secara keseluruhan berada diantara rentang nilai pada tingkat persepsi kermanfaatan yang telah ditetapkan. Dari hasil responden menyatakan bahwa penerapan sistem elektronik nomor faktur (E-NoFa) mempercepat pelaporan pajak. Penggunaan penerapan sistem elektronik nomor faktur $(E-N o F a)$ karena pengguna tidak perlu lagi datang ke KKP untuk melakakukan pelaporan pajak. Kendala yang mungkin terjadi adalah adanya masalah koneksi internet sehingga menyebabkan proses pelaporan tertunda.

Tabel 1. Hasil Analisis Regresi Persepsi mahasiswa akuntansi terhadap manfaat penerapan sistem elektonik nomor faktur (E-nofa)

\begin{tabular}{|l|c|r|r|r|c|c|}
\hline Variabel & $\begin{array}{c}\text { Tanda } \\
\text { Harapan }\end{array}$ & $\begin{array}{c}\text { Koefisien } \\
\text { Regresi }\end{array}$ & $\begin{array}{c}\text { Standar } \\
\text { Eror }\end{array}$ & t-hitung & Prob. & Signifikan \\
\hline $\mathrm{C}$ & $+/-$ & 13,979 & 12,611 & 1,109 & 0,270 & $\mathrm{~ns}$ \\
\hline $\mathrm{X}_{1}$ & + & 0,937 & 0,093 & 10,082 & 0,000 & $* * *$ \\
\hline $\mathrm{R}^{2}$ & 0,714 & $* * *:$ Signifikan pada tingkat Kesalahan $1 \%$ \\
\hline R-squared & 0,509 & \multicolumn{2}{|l}{ ns : tidak signifikan } \\
\hline S.E. of regression & 13,019 & \multicolumn{4}{l|}{} \\
\hline F-statistik & $101,653 * * *$ &
\end{tabular}

Sumber : Analisis Data Primer, 2020

Berdasarkan hasil analisis pada tabel diatas dapat diketahui hubungan (korelasi) antara manfaat penerapan dengan penerapan system elektronik nomor faktur (E-nofa) dikategorikan hubungan kuat dengan nilai 0,714 . Nilai koefisien determinasi (R-squared) sebesar 0,509, berarti 50,90 persen penerapan system elektronik nomor faktur (E-nofa) (variabel dependen) dapat dijelaskan oleh persepsi mahasiswa (variabel independen), sedangkan sisanya sebesar 49,10 persen dijelaskan oleh variabel lain 
yang tidak masuk dalam model. Hasil uji menunjukkan bahwa nilai $\mathrm{F}$ hitung ( $\alpha$ : 1\%), sebesar 101,653 lebih besar dari $F$ tabel $(6,92)$ berarti bahwa persepsi mahasiswa (variabel independen) berpengaruh nyata terhadap penerapan system elektronik nomor faktur (E-nofa) (variabel dependen).

\section{Analisis Persepsi mahasiswa akuntansi terhadap kemudahan penggunaan sistem elektronik nomor faktur $(\mathrm{E}-\mathrm{NoFa})$}

Menurut Aprilina (2012) dalam Gisbu dkk. (2015), manfaat yang diperoleh dari modernisasi administrasi perpajakan antara lain penyederhanaan alur pekerjaan (simplicity) dan kepastian dalam pelaksanaan peraturan perpajakan ( certainity) .

Peluncuran aplikasi sistem penomoran faktur pajak elektronik (E-Nofa) diharapkan dapat memudahkan orang Kena Pajak dalam menjalankan aktivitasnya dan kewajibannya di bidang perpajakan, sehingga mampu meningkatkan kepatuhan terhadap orang Kena Pajak. Hasil penelitian yang dilakukan oleh Gisbu, dkk. (2015) menunjukkan bahwa modernisasi E Nofa PPN berpengaruh positif dan signifikan terhadap kepatuhan orang Kena Pajak. Hasil penelitian yang dilakukan oleh Salim (2009) menunjukkan bahwa penerapan system online dan modernisasi dalam sistem perpajakan terbukti berpengaruh dalam meningkatkan kepatuhan dan kepercayaan masyarakat dalam melakukan pelaporan dan pembayaran pajak.

Persepsi mahasiswa akuntansi terhadap kemudahan penggunaan sistem elektronik nomor faktur ( $E$ $\mathrm{NoFa}$ ) dianalisis dengan menggunakan analisis regresi tunggal. Hasil analisis regresi tersebut disajikan pada tabel dibawah ini.

Tabel 2. Hasil Analisis Regresi Persepsi mahasiswa akuntansi terhadap kemudahan penggunaan sistem elektronik nomor faktur $(\mathrm{E}-\mathrm{NoFa})$

\begin{tabular}{|c|c|r|r|r|c|c|}
\hline Variabel & $\begin{array}{c}\text { Tanda } \\
\text { Harapan }\end{array}$ & $\begin{array}{c}\text { Koefisien } \\
\text { Regresi }\end{array}$ & $\begin{array}{c}\text { Standar } \\
\text { Eror }\end{array}$ & t-hitung & Prob. & Signifikan \\
\hline $\mathrm{C}$ & $+/-$ & 49,370 & 13,608 & 3,628 & 0,000 & $* * *$ \\
\hline $\mathrm{X}_{1}$ & + & 0,652 & 0,097 & 6,736 & 0,000 & $* * *$ \\
\hline $\mathrm{R}^{2}$ & 0,563 & $* * *:$ Signifikan pada tingkat Kesalahan $1 \%$ \\
\hline R-squared & 0,316 & \multicolumn{4}{|l}{} \\
\hline S.E. of regression & 15,365 & \multicolumn{4}{|l}{} \\
\hline F-statistik & $45,370 * * *$ &
\end{tabular}

Sumber : Analisis Data Primer, 2020 
Berdasarkan hasil analisis yang tersaji pada tabel diatas diketahui bahwa hubungan (korelasi) antara persepsi mahasiswa dengan kemudahan penggunaan sistem elektronik nomor faktur (E-NoFa) dikategorikan hubungan kuat dengan nilai 0,563 . Nilai koefisien determinasi (R-squared) sebesar 0,316, hal ini berarti 31,60 persen variabel kemudahan penggunaan sistem elektronik nomor faktur (E-NoFa) dapat dijelaskan oleh variabel independen (persepsi mahasiswa), sedangkan sisanya sebesar 68,40 persen dijelaskan oleh variabel lain yang tidak masuk dalam model. Hasil uji menunjukkan bahwa nilai $\mathrm{F}$ hitung ( $\alpha$ : 1\%), sebesar 45,370 lebih besar dari $F$ tabel $(6,92)$ berarti bahwa variabel independen (persepsi mahasiswa) berpengaruh nyata terhadap kemudahan penggunaan sistem elektronik nomor faktur ( $E$ $\mathrm{NoFa}$ )

Hasil uji $t$ terhadap variabel independen menunjukkan variabel independen (persepsi mahasiswa) berpengaruh nyata terhadap variabel kemudahan penggunaan sistem elektronik nomor faktur $(E-N o F a)$. Koefisien regresi persepsi mahasiswa bertanda positif, berarti persepsi mahasiswa berdampak pada kenaikan kemudahan penggunaan sistem elektronik nomor faktur $(E-N o F a)$.

\section{Analisis Persepsi mahasiswa akuntansi terhadap kepuasan pengguna sistem elektronik nomor faktur $(\mathrm{E}-\mathrm{NoFa})$}

Keberhasilan dari penerapan ENofa didukung oleh keberhasilan suatu sistem yang sudah diterapkan. Semua keberhasilan dari penerapan E-Nofa didukung oleh peran account representative yaitu dengan memberikan sosialisasi kepada Wajib Pajak tentang Elektronik Nomor Faktur (E-NOFA) yang merupakan suatu sistem terbaru yang dikeluarkan oleh Direktorat Jenderal Pajak yang tertuang dalam PER-24/PJ/2012 tentang Bentuk, Ukuran, Tata Cara Pengisian Keterangan, Prosedur Pemberitahuan Dalam Rangka Pembuatan, Tata Cara Pembetulan atau Penggantian, dan Tata Cara Pembatalan Faktur Pajak.

Sehingga, tujuan E-Nofa sebagai pembenahan administrasi pajak dalam penomoran faktur pajak yang akan digunakan oleh Wajib Pajak dapat berjalan dengan baik, dapat mendorong terciptanya pelaksanaan self assessment dengan lebih baik lagi dan Wajib Pajak mempunyai kesadaran untuk melaksanakan hak dan kewajiban perpajakannya sesuai dengan ketentuan perpajakan yang berlaku yang nantinya akan bermuara terhadap penerimaan pajak.

Persepsi mahasiswa akuntansi terhadap kepuasan pengguna sistem elektronik nomor faktur (E-NoFa) dianalisis dengan menggunakan analisis regresi tunggal. Hasil analisis 
regresi tersebut disajikan pada tabel dibawah ini :

Tabel Hasil 3. Analisis Regresi Persepsi mahasiswa akuntansi terhadap kepuasan pengguna sistem elektronik nomor faktur $(\mathrm{E}-\mathrm{NoFa})$

\begin{tabular}{|c|c|r|r|r|r|c|}
\hline Variabel & $\begin{array}{c}\text { Tanda } \\
\text { Harapan }\end{array}$ & $\begin{array}{c}\text { Koefisien } \\
\text { Regresi }\end{array}$ & $\begin{array}{c}\text { Standar } \\
\text { Eror }\end{array}$ & t-hitung & Prob. & Signifikan \\
\hline $\mathrm{C}$ & $+/-$ & 58,010 & 11,052 & 5,249 & 0,000 & $* * *$ \\
\hline $\mathrm{X}_{1}$ & + & 0,605 & 0,080 & 7,527 & 0,000 & $* * *$ \\
\hline $\mathrm{R}^{2}$ & 0,605 & $* * *:$ Signifikan pada tingkat Kesalahan $1 \%$ \\
\hline R-squared & 0,366 & \multicolumn{4}{|l}{} \\
\hline S.E. of regression & 14,793 & \multicolumn{5}{|l}{} \\
\hline F-statistik & $56,653 * * *$ &
\end{tabular}

Sumber : Analisis Data Primer, 2020

Berdasarkan hasil analisis yang tersaji pada tabel diatas diketahui bahwa hubungan (korelasi) antara Persepsi mahasiswa dengan kepuasan pengguna sistem elektronik nomor faktur $(E-N o F a) \quad$ dikategorikan hubungan kuat dengan nilai 0,605. Untuk nilai koefisien determinasi ( $\mathrm{R}$ squared) sebesar 0,366, hal ini berarti 36,60 persen variabel kinerja pelayanan mahasiswa dapat dijelaskan oleh variabel independen (Persepsi mahasiswa), sedangkan sisanya sebesar 63,40 persen dijelaskan oleh variabel lain yang tidak masuk dalam model. Hasil uji menunjukkan bahwa nilai $\mathrm{F}$ hitung ( $\alpha$ : $1 \%$ ), sebesar 56,653 lebih besar dari $\mathrm{F}$ tabel $(6,92)$ berarti bahwa variabel independen (Persepsi mahasiswa) berpengaruh nyata terhadap variabel kepuasan pengguna sistem elektronik nomor faktur ( $E$ NoFa).
Hasil uji t terhadap variabel independen menunjukkan variabel independen (Persepsi mahasiswa) berpengaruh nyata terhadap variabel kepuasan pengguna sistem elektronik nomor faktur (E-NoFa). Koefisien regresi Persepsi mahasiswa bertanda positif, berarti Persepsi mahasiswa berdampak pada kenaikan kepuasan pengguna sistem elektronik nomor faktur $(E-N o F a)$.

\section{KESIMPULAN DAN SARAN}

A. Kesimpulan

Berdasarkan hasil penelitian yang telah diuraikan sebelumnya, dapat disimpulkan bahwa kualitas sistem E -Nofa dan implementasi pelayanan secara parsial berpengaruh positif dan signifikan terhadap kepatuhan para pelaku usaha kena pajak. 


\section{B. Saran}

Berdasarkan hasil penelitian yang telah diuraikan sebelumnya, Direktorat Jenderal Pajak diharapkan dapat mempertahankan dan meningkatkan kualitas sistem Elektronik Nomor Faktur (E -Nofa) yang diterapkannya, hal tersebut dilakukan untuk meningkatkan kepatuhan Pengusaha Kena Pajak. Peningkatan kepatuhan Pengusaha Kena Pajak di harapkan dapat meminimalisasi penggunaan faktur pajak fiktif dan mempermudah pengawasan dalam penomoran faktur pajak, sehingga pada akhirnya dapat meningkatkan pendapatan negara.

\section{DAFTAR PUSTAKA}

(1) Direktural Jenderal Pajak. Surat Edaran Nomor: SE-20/PJ 2014 Tentang Tata Cara Permohonan Kode Dan Password. Permintaan Aktivasi Akun Pengusaha Kena Pajak Dan Sertifikat Elketronik. Serta Permintaan Pengembalian Dan Pengawasan Nomor Seri Faktur Pajak Melalui Website Direktoral Jenderal Pajak (Www.Pajak.Go.Id)

(2) Ghozali, Imam. 2007. Aplikasi Analisis Multivariate dengan Program SPSS. Cetakan ke-4. Badan Penerbit Universitas Diponegoro, Semarang.
(3) Mardiasmo. 2009. Perpajakan. Yogyakarta: Andi

(4) Moleong, Lexy J. 2014. Metode Penelitian Kuantitatif. Bandung: PT Remaja Rosdakarya

(5) Parson, Wayne. 2006. Public Policy: Pengantar Teori dan Praktek Analisis Kebijakan (Penerjemah Tri Wibowo Budi Santoso). Jakarta: Kencana

(6) Prasetyo, Bambang dan Lina M.J. 2010. Metode Penelitian Kuantitatif, Teori dan Aplikasi. PT. Raja Grafindo Persada: Jakarta Priyatno, Duwi. 2010. Teknik Mudah dan Cepat Melakukan Analisis Data Penelitian dengan SPSS dan Tanya Jawab Ujian Pendadaran. Cetakan ke-1. Gava Media, Yogyakarta

(7) Republik Indonesia, Peraturan Direktur Jenderal Pajak Nomor PER-24/pj/2012 Tentang Bentuk, Ukuran, Tata Cara Pengisian Keterangan, Prosedur Pemberitahuan dalam Rangka Pembulatan, Tata Cara Pembetulan / Penggantian dan Tata Cara Pembatalan Faktur Pajak

(8) Saningtyas, Nine Mya.2015.

"Analisis Kesiapan 
Pengusaha Kena Pajak di KPP Pratama Karanganyar dalam Penerapan Faktur Pajak Elektronik", Skripsi. Universitas Sebelas Maret, Surakarta.

(9) Waluyo. 2011. Perpajakan

Indonesia. Jakarta: Salemba Empat.

(10) Widodo, Arie dan Putu Agung Widyadnyana. 2015. "EFaktur: Satu Aplikasi
Berbagai Manfaat" $<$ http://www.ortax.org/ortax/? mod=issue \&page $\quad=$ show $\&$ id $=68>$. Diakses tanggal 02 September 2015.

(11) Yamin, Liyanto, Titi Muswati Putranti. 2009. Model Penyelewengan Pajak Menggunakan Faktur Pajak. Jurnal Ilmu Administrasi dan Organisasi 